\title{
One small step - One giant leap
}

\section{Jeewaranga Gunasekera}

Health Promotion Bureau, Ministry of Health, Sri Lanka

Correspondence: janjeewa@gmail.com

DOI: https://doi.org/10.4038/jccpsl.v24i2.8172

Received on: 11 June 2018

Accepted on: 30 June 2018

You see a group of men and women, ages ranging from young to old, organized around a table and making shoes. Vibrant tones, both of their clothes and shoes; contrasting shades of the floor; and marked vingnetting make the picture appealing. This photograph does not look any different from a regular small-scale shoe making firm, and quit rightly so, until you start wondering why the picture has been taken from a high vantage point, concealing the identities. The workers you see are psychiatric patients discharged from the National Institute of Mental Health (NIMH) Angoda, Sri Lanka.

What you witness here is the result of tireless efforts of the NIMH by collaborating with the government and private sector on empowering people with mental illness to lead a normal productive life following their initial treatment. $\mathrm{Mr}$ Ashoka Kumara, an occupational therapist from the NIMH shared the success story behind this initiative. The Industrial Development Board had

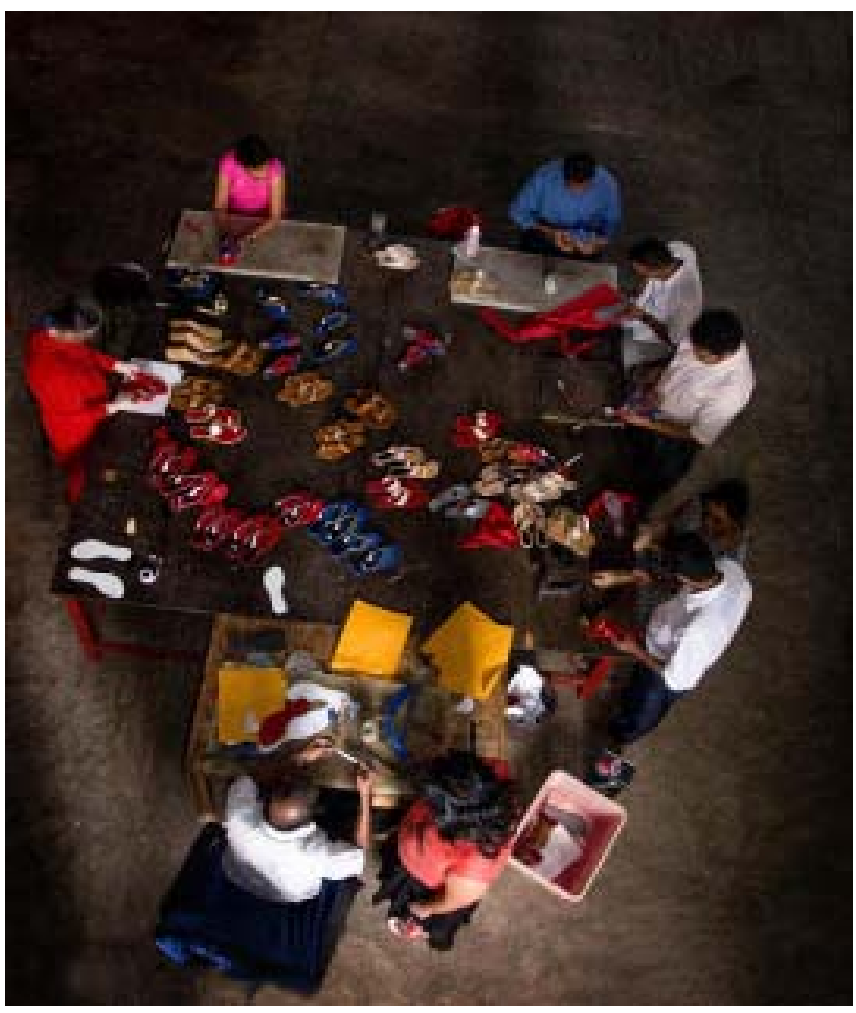
stepped forward to provide a special training programme on shoe making for this selected group of patients. Following three months of training both in theory and practical aspects, they were offered a certificate of competency. Thirteen of them who proved to be highly skilled were offered a paid internship in two large-scale private shoe manufacturing factories. While the majority of them still work as paid workers in those factories, some of them are now operating on their own.

This photograph opens the discussion on involvement of non-health sectors, both government and private, in rehabilitation and community management of psychiatric patients. Dr Jayan Mendis, consultant psychiatrist and former director of the NIMH who was instrumental in this initiative expressed his vision and progress; public-private partnership does not suit perfectly to the current traditional therapeutic model, thus success in it requires flexibility and innovation. NIMH has partnered with sectors such as insurance, manufacturing and logistics. 
The rewards of these collaborative efforts are numerous. They not only empower the patients but also provide valuable human resources to industries. The stigma towards mental illness can only be mitigated through encouraging positive interactions with the public. In recent years, companies tend to pay the full salary to the patients, even making them permanent staff members, making patients less dependent and more empowered. Acceptance by the family and society is reinforced when patients have an earning capacity. This encourages compliance towards therapy and self-esteem within patients.

Interactions and relationships created during these activities form the model of a peer group. There are even some happy love stories where patients have got married after getting to know each other through these programmes. Private organizations consider their involvement as corporate social responsibility (CSE). It helps them to improve their brand personality and public presence.

After all, mentally ill persons are an important segment in the country's work-force. Integrating them back into the system creates a new job market that corporate sector can explore. Community management of psychiatric patients have long been considered a costly affair. Public-private partnerships could be the future, if it is formally recognized as a therapeutic strategy.

\section{References}

1. Bertilsson M, Maeland S, Löve J, Jr GA, Werner EL, Hensing G. The capacity to work puzzle: a qualitative study of physicians' assessments for patients with common mental disorders. BMC Family Practice 2018; 19: 133.

2. National Institute of Mental Health. Annual Report 2016 Sri Lanka. Colombo: Ministry of Health, 2017.

3. Joint Commissioning Panel for Mental Health (JCP-MH). Guidance for commissioners of financially, environmentally, and socially sustainable mental health services. Centre for Sustainable Healthcare, 2012.

Available from: https://www.rcpsych.ac.uk/PDF/jcp\%20briefing.pdf.

4. Joint Commissioning Panel for Mental Health (JCP-MH). Guidance for commissioners of rehabilitation services for people with complex mental health needs. Centre for Sustainable Healthcare, 2016. 